\title{
Análises das embalagens de plantas medicinais comercializadas em farmácias e drogarias do município de ljuí/RS
}

COLET, C.F. ${ }^{*}$; DAL MOLIN, G.T. ${ }^{1 ;}$ CAVINATTO, A.W.'; BAIOTTO, C.S. ${ }^{1 ;}$ OLIVEIRA, K.R. ${ }^{1}$

1Curso de Farmácia. Departamento de Ciências da Vida. Universidade Regional do Noroeste do Estado do Rio Grande do Sul (UNIJUÍ). Rua do Comércio, 3000, CEP 98700-000, Rio Grande do Sul-RS.

\begin{abstract}
RESUMO: O objetivo deste estudo foi analisar as embalagens de plantas medicinais comercializadas em farmácias e drogarias do município de ljuí/RS, a partir das legislações vigentes sobre o tema. A coleta de dados foi realizada na primeira quinzena do mês de dezembro de 2011 em 13 estabelecimentos farmacêuticos localizados na região central do município, através de formulário elaborado a partir da legislação. Foram selecionadas para análise, plantas medicinais acondicionadas em diferentes tipos de embalagens e marcas. Foram avaliadas 44 embalagens de plantas medicinais, das quais $71 \%$ estavam irregulares no que se refere a indicação terapêutica e ao modo de preparo, considerando o preconizado pela RDC 10/10. Embora nem todas as drogas vegetais analisadas estivessem notificadas nesta Resolução, considerou-se o mesmo critério para todas as amostras analisadas. Além disso, $16 \%$ dos produtos analisados não apresentavam segurança quanto ao acondicionamento. A nomenclatura popular estava presente em todas as amostras, enquanto a nomenclatura botânica em apenas $75 \%$. Conclui-se que todas as embalagens analisadas apresentaram alguma irregularidade em relação ao que estabelece a RDC $n^{\circ} 10 / 2010$, tendo em vista que nenhuma apresentou todos os requisitos exigidos por ela. Os resultados observados demonstram que a ausência das informações devidas nas embalagens ou nos folhetos informativos para orientar os consumidores, pode comprometer o uso seguro das plantas e prejudicar a saúde dos usuários.
\end{abstract}

Palavras chave: Plantas medicinais, embalagem, farmácias e drogarias, comercialização de produtos.

\begin{abstract}
Analyses of the packages of medicinal plants sold in pharmacies in the city of ljuí - RS, Brazil. This study aimed to analyze the packages of medicinal plants sold in pharmacies and drugstores in the city of ljuí, state of Rio Grande do Sul, Brazil, according to the Brazilian legislation about the subject. Data collection was conducted in December 2011 in 13 selected pharmaceutical establishments located downtown, and data were collected using a form prepared from the aforementioned resolution. The medicinal plants included in the analysis were from different types of packages and brands. We evaluated 44 packages of medicinal plants, of which $71 \%$ were irregular in relation to shape, therapeutic indication and method of preparation. Moreover, $16 \%$ of the total products tested had no package security. The popular nomenclature was present in all samples, while the botanical nomenclature, in $75 \%$. We concluded that all analyzed packages were irregular according to the Brazilian RDC $10 / 2010$ because none of them had all of the requirements. The results observed, such as lack of information on the packages or leaflets to guide consumers, may compromise the safe use of plants and endanger the health of users.
\end{abstract}

Keywords: Medicinal plants, package, pharmacy, marketing products.

\section{INTRODUÇÃO}

O uso de plantas medicinais está inserido nos processos curativos desde tempos remotos. Caracteriza-se como processo cultural passado, de geração para geração, em muitos lugares do mundo, inclusive no Brasil (Carvalho, Silveira, 2010).

Com o passar do tempo, a utilização de plantas faz parte da cultura dos países e hoje está se retomando o uso e a pesquisa de plantas 
medicinais. O que se justifica pelo baixo valor econômico e pela grande variedade de espécies vegetais disponíveis na flora que podem ser usadas com finalidade curativa (Souza, Maciel, 2010).

Assim, a medicina tem redirecionado seu olhar para novas formas de utilizar plantas medicinais (Carvalho, Silveira, 2010), dando espaço aos novos produtos naturais e redescobrindo formas e indicações de uso de plantas medicinais conhecidas desde a antiguidade (Barbosa et al., 2000).

O uso de plantas medicinais é realizado com finalidade curativa e preventiva, contudo o uso popular destas terapias nem sempre possui comprovação científica de sua eficácia (Machado, 2009). Diante disso, busca-se qualificar o uso das plantas medicinais, bem como a comprovação de seus efeitos terapêuticos, composição padronizada e segurança de uso para a população (Brasil, 2010a).

Para a qualificação do uso de plantas medicinais foram instituídas legislações que visam garantir a oferta de subsídios para o uso racional de plantas medicinais e fitoterápicos através da orientação ao usuário, sobre a indicação terapêutica das mesmas, bem como informações sobre dose, posologia, formas de utilização, possíveis interações e efeitos adversos (Brasil, 2010b).

A Política Nacional de Plantas Medicinais e fitoterápicos (PNPMF) tem como objetivo construir e aperfeiçoar a produção de plantas medicinais, inserindo-as com segurança e eficácia ao Sistema Único de Saúde (SUS), assim como desenvolver incentivos para a produção, buscando conhecimento na prática popular, e garantir o uso sustentável da biodiversidade, além de desenvolver estratégia de comunicação, formação técnico-científica e capacitação nos setores de plantas medicinais e fitoterápicos (Brasil, 2006). A Resolução RDC 10/2010, que dispõe sobre a notificação de drogas vegetais junto à ANVISA, estabelece os requisitos para a embalagem destes produtos, assimo fabricante de produtos contendo plantas medicinais deve adotar, integral e exclusivamente, as informações padronizadas por esta Resolução, e atualizações posteriores, além de seguir as Boas Práticas de Fabricação e Controle de Qualidade. E ainda descreve que a embalagem deve garantir a proteção da droga vegetal contra contaminações e efeitos da luz e umidade e apresentar lacre ou selo de segurança que garanta a inviolabilidade do produto (Brasil, 2010b).

O conhecimento dos profissionais da saúde sobre as preparações com plantas medicinais e suas partes no que se refere aos benefícios e riscos potenciais, assim como da possibilidade de interagir com medicamentos, habilita estes profissionais a fornecerem esclarecimentos aos usuários, que buscam informações sobre estas terapias (Bauer, 2000).

Diante disso, o presente estudo tem como objetivo analisar as embalagens de produtos contendo plantas medicinais comercializados em farmácias e drogarias do município de ljuí/RS a partir das legislações vigentes sobre o tema.

\section{MATERIAL E MÉTODO}

Foi realizado um levantamento na primeira quinzena do mês de dezembro de 2011, em 13 estabelecimentos farmacêuticos localizados na região central do município de ljuí/RS, selecionados de forma intencional, nos quais foram selecionados 44 drogas vegetais. Foram selecionadas aleatoriamente plantas medicinais acondicionadas em diferentes tipos de embalagens e marcas, incluindo-se diversas apresentações da mesma droga vegetal. Utilizouse o conceito de estabelecimento farmacêutico da Lei 5.991/73, dividindo-os em farmácia e drogaria. Sendo farmácia o estabelecimento de manipulação de fórmulas magistrais e oficinais, de comércio de drogas, medicamentos, insumos farmacêuticos e correlatos, compreendendo o de dispensação e o de atendimento privativo de unidade hospitalar ou de qualquer outra equivalente de assistência médica; e drogaria: estabelecimento de dispensação e comércio de drogas, medicamento, insumos farmacêuticos e correlatos em suas embalagens originais (BRASIL, 1973).

Para a seleção da amostra foi utilizado o conceito de droga vegetal estabelecido pela RDC $n^{\circ} 10 / 2010$. Segundo a mesma conceitua-se droga vegetal como planta medicinal ou suas partes, que contenham as substâncias, ou classes de substâncias, responsáveis pela ação terapêutica, após processos de coleta ou colheita, estabilização, secagem, podendo ser íntegra, rasurada ou triturada (Brasil, 2010b). Foram excluídas desta pesquisa as apresentações de uma mesma droga vegetal de uma mesma marca quando encontradas em mais de um estabelecimento comercial.

Os produtos coletados e analisados foram classificados como: drogas vegetais notificadas pela RDC 10/10, chás na área de alimentos ou como plantas medicinais, conforme a Lei 5991/73.

Contudo, a análise foi realizada apenas das plantas classificadas como droga vegetal, para tal foi elaborado um formulário a partir da RDC $n^{\circ}$ 10/2010. Neste formulário foi registrada a presença ou ausência de informações técnico-científicas e de especificações exigidas pela legislação supracitada. O preenchimento do formulário foi realizado por três pesquisadores, previamente treinados, que analisaram a mesma amostra de forma

Rev. Bras. PI. Med., Campinas, v.17, n.2, p.331-339, 2015. 
independente, sendo ao final obtido um consenso das análises.

Todas as amostras foi avaliada a contaminação, para isso verificou-se exclusivamente o aspecto visual, não sendo realizados testes microbiológicos. Como neste estudo não foi realizada avaliação microbiológicas das espécies avaliadas, analisou-se apenas a integridade das embalagens e o acondicionamento do produto, sendo avaliado a presença de lacre de segurança e de algum tipo de proteção contra luz e umidade.

Também foi verificada presença ou ausência das frases obrigatórias, segundo a RDC $10 / 10$, apenas para as amostras enquadradas nesta legislação, são três frases na embalagem e dez frases no folheto informativo Embora, como mencionado, não foi considerado um critério para inclusão na amostra ser planta notificada por esta legislação. Entre as frases obrigatórias da embalagem verificou-se presença ou ausência das que seguem: a) "Este produto deve ser armazenado ao abrigo da luz, à temperatura ambiente e em locais secos."; b) "Este produto é indicado com base no seu uso tradicional."; c) "Este produto deve ser mantido fora do alcance de crianças.". As frases obrigatórias analisadas no folheto informativo foram: a) "Crianças menores de dois anos não devem utilizar este produto, já que não há estudos que possam garantir a segurança nestas situações"; b) "Mulheres grávidas ou amamentando não devem utilizar este produto, já que não há estudos que possam garantir a segurança nestas situações"; c) "O uso prolongado deste produto deve ser acompanhado por profissional de saúde"; d) "Indicado o uso para mulheres grávidas ou crianças menores de dois anos." e) "Drogas vegetais não devem ser utilizadas por período superior ao indicado, ou continuamente, a não ser por orientação de profissionais de saúde"; f) "Preparar a infusão ou, decocção imediatamente antes do uso"; g) "Se você utiliza medicamentos de uso contínuo, busque orientação de profissional de saúde antes de utilizar este produto"; h) "Este produto pode ser utilizado sem prescrição médica para o alívio sintomático de doenças de baixa gravidade por períodos curtos. Caso os sintomas persistam ou piorem, ou apareçam reações indesejadas não descritas na embalagem ou folheto informativo, interrompa seu uso e procure orientação de profissional de saúde."; i) "Maiores de setenta anos deverão utilizar metade da dose utilizada para adultos."; j) "Para crianças de três a sete anos, recomenda-se um quarto da dose utilizada para adultos; entre sete e doze anos, recomenda-se metade da dose adulta".

\section{RESULTADO E DISCUSSÃO}

Foram analisadas 45 embalagens, destas 13 eram drogas vegetais presentes no Anexo I da RDC 10/10, 13 foram classificadas como chás e 19 como plantas medicinais. Na Tabela 1, estão apresentados os dados relativos à contaminação visual e acondicionamento dos produtos encontrados nas farmácias e drogarias pesquisadas. Observouse que $84 \%$ das amostras estavam adequadas à legislação vigente, das quais $95 \%$ apresentavam selo de segurança. Contudo, não foram realizados testes laboratoriais para verificar contaminação por fungos ou outros microorganismos nesta pesquisa, sendo avaliada exclusivamente a contaminação visual, sendo esta considerada com aparência não conforme.

Das amostras analisadas, $16 \%$ dos produtos não apresentavam adequação a nenhuma das variáveis expostas na Tabela 1. Observou-se que $36 \%$ apresentavam embalagens transparentes, ficando o conteúdo exposto ao efeito da luz, além disso, algumas apresentaram vestígios de má conservação, também foi encontrada uma amostra com validade vencida.

$\mathrm{O}$ acondicionamento correto dos produtos a base de plantas medicinais, tanto pelo fabricante quanto pelos usuários, é indispensável, pois, mudanças de temperatura, luz e umidade de espécies vegetais favorecem a ação de fungos, bactérias e enzimas, o que pode ocasionar perda da qualidade do material devido à alteração e/ ou destruição dos princípios ativos responsáveis pela ação farmacológica e, ainda, a produção de substâncias tóxicas (Copetti, Griebeler, 2005).

$\mathrm{Na}$ Tabela 2, estão apresentadas as plantas medicinais encontradas com maior frequência nos estabelecimentos farmacêuticos de ljuí/RS. Foram incluídos na linha "outros", na referida tabela, aquelas plantas encontradas com menor frequência, sendo que estas representaram 54 drogas vegetais

TABELA 1. Características observadas nas embalagens dos produtos contendo plantas medicinais-analisadas em farmácias e drogarias do município de ljuí/RS. n=45

\begin{tabular}{lcccc}
\hline Característica observada & \multicolumn{2}{c}{ Ausente } & \multicolumn{2}{c}{ Presente } \\
\cline { 2 - 5 } & $\mathbf{n}$ & $\mathbf{N}$ & $\mathbf{N}$ \\
\hline Aparência não conforme da embalagem & 2 & 5 & 42 & 95 \\
Proteção contra o efeito da luz & 16 & 36 & 28 & 64 \\
Lacre ou selo de segurança & 2 & 5 & 42 & 95 \\
\hline
\end{tabular}

Rev. Bras. Pl. Med., Campinas, v.17, n.2, p.331-339, 2015. 
de 35 plantas distintas. As mesmas serão citadas, entre estas cita-se: garcinia cambogia(garcínia), Calendula officinalis (calêndula), Apium graveolens (aipo), Tabebuia impetiginosa (ipê roxo), Salvia officinalis (sálvia), Cordia trichoclada (douradinha), Plectranthus barbatus andrews (boldo) (verrrrr), Malus domestica Borkh (maça), Rosa gallica L. (rosa rubra), Senna alexandrina (sene), Carya ilinoensis (casca de nozes), Ginkgo biloba, Cynara scolymus (alcachofra), Tipuana tipu (chá tipuana), Valeriana officinalis L. (valeriana), Tilia platyphyllos Scop. (tília), Curcuma zedoaria Rosc. (zedoária), própolis Wax. C (própolis), asearia sylvestris (chá de bugre), Cereus sp. (koubo), Citrus sinensis (laranja), Passiflora alata (maracujá), Equisetum arvense (cavalinha), Cordia eucalyculata Vell (folha magra), Cinnamomum verum (canela), Litchi chinensis Sonn. (linhaça), Origanum vulgare (orégano), Camellia sinensis (chá preto), Plumeria rubra (jasmim), Rosa alba L. (rosa branca), Ananas comosus L. (abacaxi), Matricaria recutita (camomila), Cichorium endivia (chicória), Anethum graveolens (endro), Pimpinela anisum (erva doce), Hibiscus rosa-sinensis (hibisco), Passiflora alata (maracujá), Melissa officinalis (melissa).

As plantas mais prevalentes, encontradas em diferentes embalagens e marcas, foram Camellia sinensis (chá verde) com $12 \%$, a Mentha spicata (hortelã) com $8 \%$. Atualmente a grande procura pelo chá verde nos estabelecimentos farmacêuticos, está relacionada, provavelmente, ao seu emprego em dietas para redução do peso, divulgado extensivamente pelos meios de comunicação. A busca por esse tipo de produto vem crescendo pelo fato de os usuários estarem procurando formas saudáveis de vida e a convicção crescente de que todo o produto natural é saudável (Khan, Mukhtar, 2007). Segundo estes autores, no mundo são produzidas anualmente cerca de três bilhões de toneladas de matéria-prima para a produção de chá, e $20 \%$ são de chá verde, considerada uma das bebidas mais consumidas no mundo.

O uso empírico de plantas medicinais pode alterar-se de região para região, pela associação desta prática à medicina tradicional. Contudo, um levantamento realizado no Rio de Janeiro, com a população geral, profissionais de saúde e médicos evidenciou que as plantas mais utilizadas pelos entrevistados foram o Plectanthus barbatus (boldo) com $14,7 \%$ e a Chamomila recutita (camomila) com $7,0 \%$ das citações (Veiga, 2008), sendo ambas estas plantas encontradas em no estudo, representando plantas consumidas no município estudado.

Na Tabela 3, encontram-se as informações exclusivas das embalagens, exigidas pela RDC $n^{\circ}$ 10/2010. Nenhuma amostra analisada apresentouse adequada a esta legislação, por não cumprir um ou mais dos pré-requisitos exigidos.

Segundo a RDC n' 10/2010 o nome popular e a nomenclatura botânica devem estar presentes nas embalagens do produto a base de plantas medicinais, já que no Brasil, segundo Simões e Guerra (2004), há uma diversidade dessas plantas que para sua identificação são classificadas por espécie, com nome botânico, conforme suas características. Neste estudo, conforme Tabela 3, foi observado que a nomenclatura popular estava presente em todas as amostras, contudo a botânica em $77 \%$.

Outro estudo, realizado no Recife/PE, com produtos contendo plantas medicinais comercializadas em 11 supermercados e 43 farmácias do local, foram analisadas dez amostras de Aesculus hippocastanum L. (castanha-da-índia), onze de Cymbopogon citratus (DC.) Stapf (capimlimão) e seis de Centella asiatica (L.) Urban (centela

TABELA 2. As embalagens de plantas medicinais avaliadas em farmácias e drogarias de ljuí/RS

\begin{tabular}{clcc}
\hline Nomenclatura Popular & Nomenclatura Botânica & $\mathrm{N}$ & $\%$ \\
\hline Chá verde & Camellia sinensis & 13 & 12 \\
Hortelã & Mentha spicata & 9 & 8 \\
Carqueja & Baccharis trimera & 7 & 6 \\
Chá branco & Camellia sinensis & 6 & 5 \\
Cidreira & Melissa officinalis & 5 & 4 \\
Limão & Citrus limon & 4 & 3 \\
Laranja & Citrus sinensis & 4 & 3 \\
Erva mate & Ilex paraguariensis & 4 & 3 \\
Funcho & Foeniculum vulgare & 4 & 3 \\
Camomila & Matricaria recutita & 3 & 2 \\
Gengibre & Zingiber officinale & 54 & 46 \\
Outros & & 119 & 100 \\
\hline TOTAL & & & 5 \\
\hline
\end{tabular}

Rev. Bras. PI. Med., Campinas, v.17, n.2, p.331-339, 2015. 
TABELA 3. Informações exclusivas das embalagens dos produtos contendo plantas medicinais, segundo a $\operatorname{RDC} 10 / 2010 . \mathrm{N}=13$

\begin{tabular}{lcccc}
\hline Informações obrigatórias & Ausente & \multicolumn{3}{c}{ Presente } \\
\cline { 2 - 5 } & $\mathbf{N}$ & $\%$ & $\mathbf{N}$ & $\%$ \\
\hline Nomenclatura popular & 0 & 0 & 13 & 100 \\
Nomenclatura botânica & 3 & 23 & 10 & 77 \\
Notificação da ANVISA & 0 & 0 & 13 & 100 \\
Responsável Técnico & 5 & 38 & 8 & 62 \\
Número de registro & 10 & 77 & 3 & 33 \\
Lote & 3 & 23 & 10 & 77 \\
Indicação para alívio sintomático & 6 & 46 & 7 & 54 \\
Contra indicações & 12 & 92 & 1 & 8 \\
Efeitos adversos & 9 & 69 & 4 & 31 \\
Informações adicionais & 8 & 62 & 5 & 38 \\
\hline
\end{tabular}

asiática), nas informações dos rótulos, comparadas as legislações RDC no 140 de 29/05/2003 e RDC nº 102 de $30 / 11 / 2000$, constatou-se que apenas $25,93 \%$ das amostras apresentavam nomenclatura botânica oficial completa (Melo et al., 2007). Vale ressaltar que $\operatorname{RDC} 140 / 2003$ foi revogada e abordava as normas para bulas de medicamento e a RDC 102/2000, também revogada, versava sobre propaganda de medicamentos. A RDC $n^{\circ} 10 / 2010$, no artigo $2^{\circ}$ parágrafo $1^{\circ}$, apresenta a obrigatoriedade dos produtos enquadrados nesta legislação destinaremse ao uso de alívio sintomático das doenças, devendo ser disponibilizadas exclusivamente na forma de droga vegetal para o preparo de infusões, decocções e macerações. Percebemos na presente pesquisa que $46 \%$ das amostras não apresentavam indicação terapêutica, e as demais apresentavam a indicação para doenças, baseado em dados da literatura. Isso esta de acordo com pesquisa de Melo et al (2007), foram analisadas as indicações terapêuticas atribuídas as drogas vegetais e verificou-se que em $55 \%$ das embalagens as indicações informadas não eram comprovadas por estudos científicos.

Quanto à responsabilidade técnica deve constar nas embalagens o nome do farmacêutico responsável e número do Conselho Regional de Farmácia (CRF) (BRASIL, 2010b), no presente estudo estes dados estavam presentes, respectivamente, em $62 \%$ das embalagens. Em uma embalagem havia apenas o nome completo do farmacêutico responsável, estando ausente o número do CRF; e ainda em três amostras o responsável técnico era profissional da área química, contrariando a RDC $n^{\circ} 10 / 2010$, pois a mesma não prevê a responsabilidade técnica de profissional dessa classe profissional. No estudo de Bello et al (2002), em 13 farmácias distritais do município de Porto Alegre/RS, foram analisadas as embalagens de fitoterápicos, comparativamente à Portaria 110/97, sendo esta uma legislação já revogada que instituia roteiro para texto de bula de medicamentos. Sendo que nesta pesquisa o nome completo do farmacêutico responsável e o número de registro no Conselho estavam presentes em apenas $45 \%$ das embalagens dos fitoterápicos. A ausência do profissional técnico encarregado descrito nas pesquisas acima citadas é um dado preocupante, entendendo-se que não há um profissional responsável pela avaliação da qualidade físico-química e microbiológica do produto, pois pode prejudicar a qualidade dos produtos e comprometer a saúde dos usuários.

Dos 13 produtos classificados como chás, $75 \%$ destes citavam uma ou mais legislações na embalagem, havendo predomínio da RDC $n^{\circ}$ $278 / 2005$, que foi mencionada em dez embalagens, e, como mencionado, esta encontra-se revogada. Outras legislações citadas foram: RDC 23/2000 (5); RDC 216/2006 (1); art 23, Lei 6360/76 (1); Decreto $79094 / 89$ art 28 (1) que encontra-se revogado; RDC $n^{\circ}$ 360/03; Lei 23/00 (1). Além disso, 3 embalagens não citavam legislação alguma. Outras legislação citadas foram as específicas para plantas medicinais na forma de chá notificado na Anvisa, que são RDC $267 / 2005$ e 219/2006. A RDC 267/2005 aprova o regulamento técnico de espécies vegetais para preparo de chás, e exclui as com finalidade terapêutica, e apresenta uma tabela com espécies vegetais para preparo de chás. Já á RDC 219/2006, objetiva incluir espécies vegetais e partes de espécies vegetais para o preparo de chás e corrigir o nome comum ou científico de algumas espécies vegetais previstas na Resolução RDC $n^{\circ} .267$, de 22 de setembro de 2005. Estes dados indicam que há muitos produtos irregulares no mercado, que não seguem as normas sanitárias, devendo ser retirados do mercado, visando à proteção da saúde da população, uma vez que esta nem sempre apresenta o conhecimento necessário para a utilização racional destes produtos.

Contudo, vale ressaltar, que existem outras

Rev. Bras. PI. Med., Campinas, v.17, n.2, p.331-339, 2015. 
formas legais do comércio de plantas medicinais, como a lei 5991/1973; RDC 267/2005 e RDC 219/2006, segundo as quais nas embalagens não pode ter indicação terapêutica, mostrando que a maioria das drogas vegetais analisadas está seguindo o preconizado por esta legislação. Isso esta associada a parte das plantas analisadas no estudo constar nas tabelas em anexo da RDC 267/2005 e RDC 219/2006. Contudo, entre as plantas classificadas como chás (13) e como plantas medicinais (19), 60\% das mesmas apresentavam indicação terapêutica nas embalagens.

O mesmo foi observado no estudo de Ethur et al (2011) que não encontraram a indicação para uso terapêutico das plantas medicinais nas embalagens, entretanto, no referido estudo, estas informações eram disponibilizadas em folhetos nos balcões das farmácias. Contudo, os autores destacam que nem todos os consumidores acessavam esse material.

As informações apresentadas na Tabela 4 deveriam estar presentes, segundo a legislação vigente, em um folheto informativo presente na embalagem da droga vegetal, contudo não foi encontrado o folheto em nenhum dos produtos analisados, sendo que em alguns, as informações preconizadas estavam impressas na embalagem. Esses dados justificam-se por parte da amostra analisada não ser notificada pela RDC 10/10. Portanto, as informações presentes na referida tabela foram retiradas da embalagem dos produtos. Observou-se que $68 \%$ das embalagens não apresentavam as informações exigidas pela legislação. Para esta análise utilizou-se apenas as 13 amostras classificadas como droga vegetal notificada.

A carência de informações verificadas nesses produtos também foi evidenciada em estudo realizado em Recife/PE, no qual foram analisadas 24 marcas de produtos fitoterápicos comercializadas em 54 farmácias, sendo oito de Peumus boldus Molina (boldo), nove de Bauhinia spp. (pata-devaca) e sete de Ginkgo biloba. Foram analisados os rótulos e bulas dos produtos verificando se estavam de acordo com a RDC $n^{\circ} 17 / 2000$ e a Portaria $n^{\circ} 110 / 97$, respectivamente de registro e bula de produtos. Neste estudo foi constatado que $95,86 \%$ das amostras não apresentavam a bula exigida pelas legislações, apenas um produto composto por Ginkgo biloba apresentou bula, e os demais somente rótulos ou etiquetas com informações incompletas acarretando ausência de informações técnicas completas e indispensáveis para o consumidor (Melo et al, 2004).

Segundo os autores acima citados, as informações específicas como ação dos produtos vegetais, assim como, contra indicações, precauções, reações adversas, interações medicamentosas, modos de administração e cuidados no armazenamento, devem estar presentes na bula destes produtos, sendo que a ausência destas informações pode levar ao uso indevido, alterações das funções orgânicas no estado natural do indivíduo e trazer prejuízos para a saúde do mesmo (Melo et al, 2004). Estas constatações se estendem neste estudo uma vez que apenas $18 \%$ das embalagens apresentavam contra indicações e $31 \%$ incluíam os efeitos adversos.

No estudo de Bello et al (2002), também foi verificada ausência de informações sobre reações adversas $(42,2 \%)$, contra indicação $(24,2 \%)$, uso na gravidez e lactação $(42,4 \%)$, interrupção do tratamento $(78 \%)$ e ingestão concomitante com outras substâncias (70\%), podendo induzir o usuários a acreditar que os medicamentos fitoterápicos e plantas medicinais são produtos inócuos e que não apresentam contra indicação, sendo seu consumo livre, independente do outros fatores.

Em Campina Grande/PB, foi realizado um

TABELA 4. Informação exclusiva do folheto informativo dos produtos à base de plantas medicinais, de acordo com a RDC 10/2010, analisadas no município de ljuí/RS. n=13

\begin{tabular}{lcccc}
\hline \multirow{2}{*}{ Informações obrigatórias } & \multicolumn{2}{c}{ Ausente } & \multicolumn{2}{c}{ Presente } \\
\cline { 2 - 5 } & $\mathbf{N}$ & $\mathbf{\%}$ & $\mathbf{n}$ & $\%$ \\
\hline Parte utilizada da planta & 3 & 33 & 10 & 77 \\
Posologia e modo de utilização & 2 & 15 & 11 & 85 \\
Informação para criança & 11 & 85 & 2 & 15 \\
Informação para idoso & 13 & 100 & 0 & 0 \\
Informação para gestante & 12 & 92 & 1 & 8 \\
Forma de utilização da droga vegetal & 1 & 8 & 12 & 92 \\
Apresenta a palavra "chá" & 11 & 85 & 2 & 15 \\
Utilização dos medicamentos contínuos & 13 & 100 & 0 & 0 \\
Apresenta dose individual ou medidor & 11 & 85 & 2 & 15 \\
\hline
\end{tabular}

Rev. Bras. Pl. Med., Campinas, v.17, n.2, p.331-339, 2015. 
estudo no mercado informal de plantas medicinais, acerca do uso de medicamentos e/ou fitoterápicos, sendo a amostra composta por 14 herbolários. Dentre os entrevistados, $50 \%$ acredita que produtos vegetais são isentos de efeitos adversos. Este dado demonstra que a população estudada subestima as propriedades tóxicas das plantas e, muitas vezes, fazem uso sem conhecimento de todos os seus efeitos. Este dado é ainda mais preocupante uma vez que estes herbolários influenciam a população no uso destas terapêuticas (França et al, 2008). Segundo a Lei 5.991/1973, conceitua-se ervanaria como estabelecimento que realize dispensação de plantas medicinais.

Nas embalagens de droga vegetal a legislação vigente estabelece que seja apresentada a parte da planta utilizada na composição do produto, contudo essa informação estava ausente em 33\% das amostras. Nas embalagens, que apresentavam a parte da planta, foram descritas as seguintes partes, havendo citação, em alguns casos, de mais de uma parte da planta: flor $(45 \%)$, fruto $(25 \%)$, folha $(23 \%)$, casca $(18 \%)$, caule $(18 \%)$, ramos $(13 \%)$, broto $(6 \%)$, rizoma $(6 \%)$, talos $(4 \%)$ sementes (2\%), raiz (1\%). Segundo o Informe Técnico $n^{\circ} 45$ da área de alimentos da ANVISA de 2010 (Brasil, 2010b), é importante informar ao usuário que não são todas as espécies vegetais, nem qualquer parte da planta, que podem ser utilizadas para o preparo de chás. Além da falta da informação sobre a parte da planta que consta nas embalagens, $29 \%$ destas não apresentava o modo de preparo. Segundo Simões e Guerra (2004) a forma de preparo está relacionada com a parte da planta que será utilizada, sendo que partes lenhosas ou mais densas da planta, como raiz, caule e/ou casca, devem ser preparadas na forma de da decocção, e as partes da planta mais perenes devem ser preparadas por infusão. Contudo, como a maioria das embalagens não consta a parte da planta, pode ocorrer dúvidas e erros relacionados ao preparo que podem ocasionar inefetividade terapêutica.

Ainda no que se refere a informações sobre a parte da planta a ser utilizada no preparo dos produtos contendo plantas medicinais, em outro estudo realizado em 54 farmácias de Recife/ PE foram analisadas oito amostras de Pimpinella anisum, I. (Erva-doce), dez amostras de Phyllanthus niruri L. (Quebra-pedra), oito amostras de Matricaria recutita L., (Camomila) e seis amostras de Maytenus Ilicifolia Mart. (Espinheira Santa) e 71,8\% das amostras apresentavam a parte da planta que foi utilizada. Em uma amostra constava uso do talo da planta, sendo avaliada como um erro de interpretação do fornecedor (Nascimento et al, 2005). A falta de informações sobre a parte da planta utilizada também foi notificada no trabalho de Melo et al (2004), no qual de 24 produtos analisados, $29,1 \%$ não mencionavam na embalagem a parte da planta utilizada.

Para drogas vegetais notificadas pela RDC $10 / 10$, as informações presentes nos produtos à base de plantas medicinais estas devem subsidiar o uso em criança, adulto, gestantes e/ou mulheres amamentando e idosos, informando sobre dosagem, precauções e modo de preparo para cada planta medicinal. Contudo, as informações quanto ao uso em criança estavam ausentes em $85 \%$ das embalagens, $92 \%$ não continham informações sobre uso em idosos e em nenhuma embalagem havia informações sobre uso em adultos e gestantes. A falta destas informações pode causar dúvidas nos consumidores quanto à segurança do uso da planta em determinada condição fisiológica ou de idade do usuário. Além de poder gerar uso irracional das espécies vegetais que podem culminar em intoxicações. Embora essas informações não sejam obrigatórias para todas as embalagens que fizeram parte da amostra sua presença pode auxiliar no uso racional destes produtos.

Uma das frases que deveria estar presente no folheto refere-se à utilização de droga vegetal associada a medicamentos de uso contínuo, sugerindo a busca de orientação com profissional de saúde antes do uso do mesmo. Essa informação não foi encontrada nas embalagens analisadas, 0 que de acordo com Pinn (2001) pode representar um risco à saúde do usuário de terapia associada, uma vez que muitas plantas minimizam, aumentam ou se opõem aos efeitos dos medicamentos. Também precisa constar no folheto informativo a orientação sobre o uso prolongado do produto, que só pode ser realizado mediante o acompanhamento de profissional da saúde, o que se constitui em um alerta ao usuário em relação aos riscos relacionados ao uso de plantas medicinais e implica no seguimento do usuário, bem como no comprometimento tanto deste quanto de um profissional da saúde, que pode ser o farmacêutico, com o uso contínuo do produto. Contudo, nesta pesquisa, esta orientação não foi encontrada em nenhuma embalagem analisada.

A legislação versa sobre a necessidade de cada embalagem conter doses individuais ou medidor apropriado à dose que deve ser utilizada. Diante disto, neste estudo, foram consideradas adequadas as embalagens com apresentação em sachês, que representaram $18 \%$ do total de embalagens analisadas. Em nenhum dos produtos analisados, embalados a granel, foi encontrado medidor apropriado. Considerando que os usuários podem utilizar em quantidades insuficientes ou até superiores as doses indicadas para ter ação farmacológica da droga vegetal. A falta de informações sobre a indicação terapêutica e a 
quantidade necessária de droga vegetal pode gerar risco à saúde dos usuários. Um estudo realizado com portadores de câncer na rede pública da saúde de João Pessoa/PB abordou as indicações terapêuticas e concluiu que $70 \%$ dos entrevistados não buscam informações complementares sobre plantas utilizadas por considerarem que "se bem não fizer, mal não fará". Contudo as plantas são produtos naturais que podem provocar efeitos indesejados, tóxicos ou mesmo interagirem com os medicamentos convencionais em uso (Araújo et al., 2007).

Conforme a RDC no 10/2010 em seu artigo $14^{\circ}$ a denominação "chá" não deve ser utilizada para designar o produto, podendo constar apenas nas informações sobre forma de utilização (BRASIL, 2010b). Contudo, na presente pesquisa, entre as plantas classificadas como droga vegetal, $15 \%$ das embalagens apresentavam a palavra "chá" para identificar o produto, sendo que a restrição desta palavra pela legislação é justificada pela palavra "chá" designar três tipos de bebida: o preto, o verde e o branco, obtidos da planta Camellia sinensis. Popularmente, porém, a palavra chá é usada para infusões feitas com outras ervas (Kunh \& Winston, 2000). O fato de utilizarem essa palavra demostram que as embalagens estão seguindo o preconizado pelas legislações 5991/73; RDC 267/05; RDC 219/06.

Além disso, a RDC $n^{\circ} 277$, de 22 de setembro de 2005, define chá como: "o produto constituído de uma ou mais partes de espécie(s) vegetal (is) inteira(s), fragmentada(s) ou moída(s), com ou sem fermentação, tostada(s) ou não, constante de Regulamento Técnico de Espécies Vegetais para o Preparo de Chás. O produto pode ser adicionado de aroma e ou especiaria para conferir aroma e ou sabor". Esta mesma Resolução o item 3.2 descreve que este produto deve ser designado "Chá", seguido do nome comum da espécie vegetal utilizada, podendo ser acrescido do processo de obtenção e ou característica específica, podendo ser utilizadas denominações consagradas pelo uso.

Diante do exposto, o estudo constatou irregularidade em todas as embalagens analisadas nas farmácias e drogarias em estudo, classificadas de acordo com a RDC no 10/2010, uma vez que nenhuma embalagem atende todos os requisitos exigidos pela legislação. Esta, embora encontra-se em vigor há dois anos, não está sendo cumprida pelos fabricantes de produtos à base de plantas medicinais. Neste sentido verifica-se a necessidade de constantes ações de controle sanitário nesta área, visando à proteção à saúde da população, uma vez que a mesma nem sempre apresenta o conhecimento necessário para fazer um uso racional destes produtos, e que é papel das agências regulamentadoras da saúde e dos profissionais da saúde oferecer subsídios para a construção desse conhecimento.

Cabe salientar que foram diagnosticados problemas relacionados ao acondicionamento das plantas nas embalagens, e encontrou-se um produto vencido na área de comercialização de uma drogaria.

A ausência de informações nas embalagens ou em folhetos informativos, como verificado nesse estudo, pode comprometer o uso das plantas medicinais, uma vez que estas podem apresentar baixa qualidade, além de equívocos relacionados com uso e formas de preparo. Foi verificada a falta de informações específicas sobre uso, destes produtos analisados, em crianças e idosos, este dado é preocupante, pois tratam-se de grupos de risco que podem ser prejudicados considerando efeitos colaterais mais pronunciados descritos nestas populações.

Diante do exposto, verifica-se que além dos estudos pré-clínicos e clínicos comprovando as propriedades farmacológicas de plantas medicinais, são fundamentais estudos de controle de qualidade e estudos para determinação da parte utilizada e do melhor método extrativo. Considerando que, mesmo que se disponibilize uma planta medicinal cujos efeitos sejam comprovados, isto não garante um uso seguro, já que o mesmo está associado também ao seu processo de beneficiamento, acondicionamento e a disponibilização de informações necessárias ao uso racional e respaldadas por legislação.

Por fim, esta pesquisa mostra a necessidade de novos estudos de maior abrangência e em outras populações. Além disso, estes estudos são necessários para auxiliar no controle do mercado de produtos contendo plantas medicinais, mostrando a falha no cumprimento da legislação vigente e a necessidade de ações para maior controle neste setor.

\section{REFERÊNCIAS}

ARAÚJO, E.C.; OLIVEIRA, R.A.G.; CORIOLANO, A.T.; ARAÚJO, E.C. Uso de Plantas Medicinais pelos pacientes com câncer de hospitais da rede pública da saúde em João Pessoa (PB). Revista Espaço para a Saúde, v.8, n.2, p.44-52, 2007.

BARBOSA, A.S.; SOUSA, E.G.; SILVA, M.A.; OLIVEIRA, H. S. M. C. ; MEDEIROS, M. B. Plantas medicinais: aspectos do uso de fitoterápicos na melhoria da qualidade de vida humana. In: X Encontro de Iniciação à docência Paraíba. Paraiba, UFPB, 2000. p.6

BAUER, B.A. Herbal Therapy: what a clinician needs to know to counsel patients effectively. Mayo Clinic Proceedings, v.75, n.8, p.835-41, 2000. 
BELLO, C.M.; MONTANHA, J.A.; SCHENKEL, E.P. Análise das bulas de medicamentos fitoterápicos comercializados em Porto Alegre, RS, Brasil. Revista Brasileira Farmacognosia, v.12, n.2, p.75-83, 2002.

BRASIL. Ministério da Saúde. Secretaria de Ciência, Tecnologia e Insumos Estratégicos. Departamento de Assistência Farmacêutica. Política Nacional de Plantas Medicinais e Fitoterápicos. Brasília: Ministério da Saúde, 2006. 60 p.

BRASIL. Ministério da Saúde. Resolução RDC n² 277, de 22 de setembro de 2005. Aprova o "Regulamento técnico para café, cevada, chá, erva-mate e produtos solúveis". Diário Oficial da União; Poder Executivo, de 23 de setembro de 2005.

BRASIL. Ministério do Desenvolvimento Agrário. Nota técnica $\mathrm{n}^{\circ} \mathbf{1}$ do Comitê Nacional de Plantas Medicinais e Fitoterápicos (CNPMF). Brasília: Ministério do Desenvolvimento Agrário, 2010.

BRASIL. Agência Nacional de Vigilância Sanitária. Resolução RDC n $^{\mathbf{1 0}}$, de 9 de Março de 2010. Dispõe sobre a notificação de drogas vegetais junto à Agência Nacional de Vigilância Sanitária (ANVISA) e dá outras providências. Disponível em: <http://www.anvisa.gov. $\mathrm{br} /$ medicamentos/fitoterapicos/definicao.htm> Acesso em: 03 de nov. 2011.

CARVALHO, A.C.B; SILVEIRA, D. Drogas vegetais: a antiga nova forma de utilização de plantas medicinais. Brasília Médica, v.47, n.2, p. 219-37, 2010.

COPETTI, F.B.; GRIEBELER, S.A. Análise da adequação da rotulagem de medicamentos fitoterápicos. Infarma, v.17, n 7/9, p. 60-4, 2005.

ETHUR, L.Z; JOBIM, J.C; RITTER, J.G; OLIVEIRA, G; TRINDADE, B.S. Comércio formal e perfil de consumidores de plantas medicinais e fitoterápicos no município de Itaqui- RS. Revista Brasileira de Plantas Medicinais, v.13, n.2, p. 121-8, 2011.

FRANÇA, I.S.X.; SOUZA, J.A.; BAPTISTA, R.S.; BRITTO, V.R.S. Medicina popular: benefícios e malefícios das plantas medicinais. Revista Brasileira de Enfermagem, v.2, n.61, p. 201-08, 2008.

KHAN, N.; MUKHTAR, H. Tea polyphenois for health promotion. Live Sciences, v.81, n.7, p. 519- 33, 2007.
KUHN, M.A; WINSTON, D. Herbal therapy and supplements. Philadelphia: Lippincott. 2000. p. 89-92

MACHADO, L.H.B. As representações entremeadas no comércio de plantas medicinais em Goiânia/GO: uma reflexão geográfica. Sociedade \& Natureza, v. 21, n.1, p. 159-72; 2009.

MELO, J.G.; NASCIMENTO, V.T.; AMORIM, E.L.C.; ANDRADE L.C.S.; ALBUQUERQUE, U.P. Avaliação da qualidade de amostras comerciais de boldo (Peumus boldus Molina), pata-de-vaca (Bauhinia spp.) e ginco (Ginkgo biloba L.). Revista Brasileira Farmacognosia, v. 14, n. 2, p.111-20, 2004.

MELO, J.G.; MARTINS, J.D.G.R.; AMORIM, E.L.C.; ALBUQUERQUE, U.P. Qualidade de produtos a base de plantas medicinais comercializados no Brasil: castanhada-índia (Aesculus hippocastanum L.), capim-limão (Cymbopogon citratus (DC.)Stapf) e centela (Centella asiatica (L.) Urban). Acta Botânica Brasileira, v. 1; n. 21; p. 27-36, 2007.

NASCIMENTO, V.T.; LACERDA, E.U.; MELO, J.G.; LIMA, C.S.A.; AMORIM, E.L.C.; ALBUQUERQUE, U.P. Controle de qualidade de produtos à base de plantas medicinais comercializados na cidade do Recife-PE: erva-doce (Pimpinella anisum L.), quebra-pedra (Phyllanthus spp.), espinheira santa (Maytenus ilicifolia Mart.) e camomila (Matricaria recutita L.). Revista Brasileira Plantas Medicinais. v.7, n.3, p.56-64, 2005.

PINN, G. Adverse effects associated with herbal medicine. Australian Family Physician. v. 30, n.5, p.1070-5, 2001.

SIMÕES, C.M.O.; GUERRA, M.PG. Farmacognosia: da planta ao medicamento. 5. ed. Porto Alegre: UFRGS, 2004.1120p.

SOUZA, F.S; MACIEL, C.C.S. Produtos fitoterápicos e a necessidade de um controle de microbiológico. Revista Eletrônica de Ciências, v. 3, n. 2, p.22-30, 2010.

VEIGA, V.F.J. Estudo do consumo de plantas medicinais na Região Centro-Norte do Estado do Rio de Janeiro: aceitação pelos profissionais de saúde e modo de uso pela população Revista Brasileira Farmacognosia v. 2 , n. 18, p.308-13, 2008. 